\title{
Avoiding the complications of parotidectomy for benign disease: Intraoperative techniques
}

\author{
Ayman A Albatanony, ${ }^{a, b} M D ;$ Azzam Alkadi, ${ }^{a} M D$; \\ Ayman H Elgadaa, ${ }^{a, c} M D$
}

a) Department of Surgery, Qassim College of medicine, Qassim, Buraida, KSA. b) Department of General Surgery, Menoufiya University, Shibin Alkom, Egypt. c) Department of General Surgery, Zagazig University, Zagazig, Egypt.

\begin{abstract}
Parotidectomy for benign disease is the most common indication for parotidectomy. Surgical treatment of benign parotid disease remains a challenging undertaking that is associated with significant postoperative morbidity. The aim of this study is to present our experience with a series of 29 cases of superficial parotidectomies, regarding the incidence of the common complications and the techniques we used to reduce the incidence of these complications. We encountered 2 cases (6.9\%) of facial nerve dysfunction; both were of a mild degree. We used Ligasure, loupes, nerve monitoring and certain intra operative techniques to achieve such a low incidence of facial nerve dysfunction. No case of Frey syndrome was encountered, due to the use of expanded poly tetrafluoroethylene sheets. Only 3 cases suffered partial anaesthesia of the ear pinna, as we preserved the trunk or the posterior branch of the great auricular nerve. Salivary fistula occurred in $17.2 \%$ of cases, and was mild and was treated conservatively. We recommend sticking to our techniques to decrease the postoperative complications of parotidectomy.

Key words: Parotidectomy, complications, operative techniques.
\end{abstract}

\section{Introduction:}

Parotidectomy for benign disease is the most common indication for parotidectomy, ${ }^{1}$ and superficial parotidectomy (entailing the removal of the parotid tissue lateral to the facial nerve and its branches, ${ }^{2}$ is the most frequently performed type of parotidectomy. ${ }^{3}$

Parotid gland surgery is problem-prone due to two main facts: firstly, the indication is usually benign, hence the patients expect no complications post-operatively, ${ }^{4}$ and secondly: it is a technically sensitive surgery because of the close relationship of the gland with the extra-cranial facial nerve which is a motor supply to the muscles of facial expression. ${ }^{5}$

Complications of parotid surgery may be intra-operative or post-operative., early or late. Intra-operative complications of parotid gland surgery comprise injury of the facial nerve or one of its branches, rupture of the pseudo- capsule of a parotid tumour or incomplete surgical resection thereof. ${ }^{4}$

A few of the expected consequences following parotidectomy are ear numbness that may be temporary or permanent, ${ }^{2}$ and occasional problems with mastication (gustatory sweating, flushing, itching...).6,7

Surgical treatment of benign parotid disease remains a challenging undertaking that is associated with significant postoperative morbidity. Some complications are inherent in the nature of the pathology for which the operation is undertaken; and these need to be taken into account in preoperative decision making and patient counselling. Others, however, can result from variations in surgical practice and could potentially be avoided. ${ }^{8}$

In this article we present our experience with a series of 29 cases of superficial parotidectomies, regarding the incidence of 
the common complications and the techniques we used to reduce the incidence of these complications.

\section{Patients and methods:}

A retrospective review of 29 consecutive superficial parotidectomies, conducted at the hospitals affiliated with Qassim College of medicine, Qassim, KSA, between the January 2009 and January 2012. The pathology reports, operative data and the postoperative course of each patient were studied.

None of the surgeries was a redo parotid surgery and none of the patients had preoperative facial nerve affection on clinical basis.

\section{Surgical technique:}

Hypotensive anaesthesia was used whenever possible. Long-acting paralytic agents are avoided to allow for facial nerve monitoring. ${ }^{9}$ The operator used a magnifying loupe in all cases (x2.5-3.5). Intra operative facial nerve monitoring through a nerve stimulator was used in every case and to facilitate this, transparent drapings were used. ${ }^{10}$ Typically four electrodes are placed trans-cutaneously in the facial musculature to correspond to the temporal, zygomatic, buccal, and marginal mandibular branches of the facial nerve. ${ }^{2}$

The surgery was carried out through a modified Blair incision or a modified face-lift incision. ${ }^{11}$ The skin in the parotid area was infiltrated with 1:80,000 adrenaline. ${ }^{5}$

Methylene blue was used to mark points along the proposed incision and to facilitate proper wound alignment and closure. The skin incision is made with a scalpel and carried down through the subcutaneous tissues and platysma muscle.

An anterior flap was raised trying to keep it as thick as possible, avoiding violation of any neoplasm at the surface of the gland.

A posterior, inferior flap is also elevated to expose the tail of the parotid gland. Silk sutures were used to retract these flaps.

Every effort was made to preserve the great auricular nerve, but if its division was judged to be imperative for a safe identification \& dissection of the facial nerve; or to prevent tumour cell dissemination, it was sacrificed preserving its posterior branch. ${ }^{12} \mathrm{We}$ employed the techniques advised by Vieira et al in $2002 .{ }^{13}$

The posterior belly of the digastric muscle is exposed with further elevation of the tail of the parotid gland. During elevation of the tail of the parotid, the continuity of the posterior facial vein is preserved if possible.

The posterior belly of the digastric muscle serves as a landmark for the facial nerve. The facial nerve is identified using anatomic landmarks, which include the posterior belly of the digastric muscle, the mastoid tip, the tragal cartilage pointer, and the tympanomastoid suture. ${ }^{2}$

Anterior retraction of the parotid gland was kept gentle, to avoid traction injury of the facial nerve and its branches. Traction was suggested by Nouraei et al to be the main cause of injury to the marginal mandibular branch, the most commonly injured branch. ${ }^{8}$

After identification of the facial nerve trunk, the parotid gland superficial to the nerve is divided carefully. This was achieved by passing a fine mosquito forceps above and parallel to the nerve, spreading it open, elevating it and then, the parotid tissue above it is removed using a Ligasure Precise ${ }^{\circledR} .{ }^{14}$ This was repeated tracing the facial nerve branches distally till removing the whole parotid gland lateral to the nerve. Anatomic distortion by a neoplasm or operative manipulation was constantly considered. In no case we needed to do a retrograde facial nerve dissection.

After the gland was removed, the wound was carefully inspected and bleeding sites were controlled, if any. The integrity of the facial nerve is confirmed both visually and by electrical stimulation of the main trunk of the facial nerve and its peripheral branches.

Before skin closure, defect filling in the parotid area was performed in all patients. An expanded polytetrafluoroethylene (e-PTFE) (GoreTex®) sheet was used. Parotid duct was not sought nor ligated routinely. The wound is irrigated, realigned, and closed in layers on a suction drain.

\section{Results:}

Data were presented either as means with standard deviations or as percentages when appropriate. 


\section{Demographic data:}

Out of the 29 patients included in this study there were 18 men $(62 \%)$ and 11 women. The average age was $51 \pm 11.6$ years (range: $29-73$ years). The right side was affected in $56 \%$ of cases. Benign parotid neoplasms (pleomorphic parotid adenoma, adenolymphoma and parotid lipoma) were the cause of surgery in 26 patients and chronic inflammation in 3 patients. The average operative time was $151 \pm 40.2$ minutes (range: 120-223 minutes). In no case the intra operative blood loss exceeded $140 \mathrm{ml}$.

\section{Post operative facial nerve affection:}

Facial nerve function was evaluated at 1 day, 1 month and 6 months postoperatively, using the House-Brackmann grading system. ${ }^{15}$

A degree of facial nerve affection was found in 2 cases $(6.9 \%)$ in the study group. According to the House-Brackmann grading system, the affection was mild in both cases (i.e. grade 2 and 3 ), and both regained normality by the end of the 6 months follow-up period. Both cases were inflammatory not neoplastic cases. Frey syndrome (gustatory sweating):

All the patients were assessed clinically for the presence of Frey syndrome at one and six month's visits. None of the patients complained of Frey syndrome or other problems related to mastication.

\section{Anaesthesia/parathesia in the ear pinna:}

3 patients (10.3\%) complained of a degree of anaesthesia in the ear pinna that was tolerable and were improving on the 6 month follow up visit.

No post operative haemorrhage nor infection were reported. Transient salivary fistula was noted in 5 patients $(17.2 \%)$ and both settled within a few weeks of conservative treatment. Seroma was reported in 4 cases, and all were treated with repeated aspiration and disappeared within 3 weeks of surgery. 1 case developed a keloid at the scar site. Recurrence of the tumour was not evaluated due to the short follow up period.

\section{Discussion:}

The incidence of facial nerve dysfunction in our study was $2 / 29(6.9 \%)$, and both cases were mild affection that improved completely within few months of surgery ( 1 case resolved in 6 weeks, and 1 case in 16 weeks). The incidence and severity of facial nerve affection in the current study is lower than that reported by many authors. Nouraei et al in 2008 wrote: "Postoperative facial nerve dysfunction is a common finding, affecting $30-60 \%$ of patients following parotidectomy, and although most cases are transitory in nature, it can, nevertheless, be associated with significant morbidity and distress". 8

According to Wang and Eisele, temporary facial nerve paralysis involving all or just one of the branches of the nerve occurs in 10-30\% of parotidectomies. 2 In 2011, Amin et al reported that 2 cases out of $23(8.7 \%)$ developed transient facial nerve affection. ${ }^{17}$

The relatively low incidence in the current study was the cumulative effect of many factors. Hypotensive anaesthesia helped in maintaining a dry field as did the local infiltration with adrenaline. The use of a surgical loupe allowed better identification of the tissues, a subtle step overlooked by quite a few surgeons; for example Sharma and Sirohi in 2010 reported 5/17 (29.4\%) of facial nerve dysfunction postoperatively when no magnification was used..$^{5}$ The value of using the loupe was also pointed out by Papadogeorgakis et al ${ }^{18}$ and Pai. ${ }^{19}$

Identification of the main trunk of the facial nerve was a crucial step. One should avoid going directly to the facial nerve trunk area before identifying the anatomic landmarks. ${ }^{20}$ In this study we followed the time-honoured classical 4 landmarks. ${ }^{2}$ There are more than 15 landmarks that can be used for identification of the main trunk of the facial nerve, ${ }^{21}$ however, we found the classic four ones more consistent, specially the tragal pointer. This was in accordance with Rea et al, who studied these four landmarks extensively. ${ }^{22}$ A modification of the use of these 4 landmarks was proposed by Pereira et al, and we also found this technique helpful. ${ }^{23}$ The advices of O'Brien et al were also honoured. ${ }^{24}$

Intra-operative facial nerve monitoring helped in decreasing the incidence of facial nerve dysfunction. It was pointed out by Pienkowski et al in 2010 that intra-operative facial nerve monitoring should be a standard procedure during parotid gland surgery in most clinical situations. ${ }^{10}$ Lowry et al also found 
that the use of facial nerve monitoring reduced the likelihood of the surgeon being sued by more than $20 \% .^{25}$ Another subtle step is ignoring the parotid duct. It is better not to be sought for nor ligated. Olsen in 2004 advised "do not look for the parotid duct or try to isolate it after raising the cheek flap as this puts an unnecessary risk of injuring the small buccal nerve branches that often accompany the duct". ${ }^{26}$ We also believe that using the Ligasure Precise ${ }^{\circledR}$ for dissection was a crucial step. The incidence of facial nerve injury in this study $(6.9 \%)$ is comparable to that reported by Michel et al (4\%), who used a tissue welding forceps for dissection during parotidectomy. ${ }^{27}$ An interesting finding in our study is that both cases of facial nerve affection were encountered in inflammatory cases. This is in accordance with Gaillard et al., 2005.28 We depended on the clinical-based system for evaluation of facial nerve function because it is evident that there is no subclinical affection of facial nerve following parotidectomy, ${ }^{16}$ hence no need for electro-physiological evaluation.

Frey syndrome is a quite common and unpleasant complaint, observed in up to $40 \%$ of patients after parotidectomy and is a potential cause of patient embarrassment, and may limit the patient's quality of life. ${ }^{7}$ We encountered no cases suffering clinically from Frey syndrome within the 6 months follow up period. The factors contributing to this in our opinion are mainly two factors: keeping the raised flaps as thick as possible without risking opening the tumour pseudo-capsule, and more importantly, the mechanical barrier we used, i.e. the e-PTFE sheet. The insertion of the mechanical barrier virtually eliminates any possibility of Frey syndrome, as it prevents the cross regeneration of nerve fibers, the hypothesis agreed to be the cause of this syndrome. ${ }^{29}$ Guo et al in 2005 reported also a zero percent incidence of Frey syndrome in ePTFE-implanted cases. ${ }^{30}$

Many types of mechanical barriers were described (Oxidized regenerated cellulose, ${ }^{31}$ Lyophilized Dura and polyglactin \& polydioxanone mesh, ${ }^{32}$ dermofat graft, ${ }^{33}$ fat injection, ${ }^{7}$ superficial temporal artery fascia flap $^{34} \&$ superiorly based superficial sternocleidomastoid flap, ${ }^{17}$ ) but in many respects, e-PTFE implants represent the ideal solution since they are not resorbed, exhibit good biocompatibility, and low tissue reactivity. ${ }^{35} \mathrm{We}$ also agree with Guo et al that the aesthetic effects of the use of e-PTFE were very good. The advantage of being nonabsorbable was also a disadvantage of e-PTFE, as it acts as a foreign body in the wound, thus causing salivary fistula. We encountered 5 cases $(17.2 \%)$, a percentage that is lower than that reported by Dulguerov et al in 1999, who reported a $25 \%$ incidence of salivary fistula in the e-PTFE-implanted patients. ${ }^{32}$ All the fistula cases in our study, as in theirs', eventually closed with conservative treatment.

We managed to preserve the great auricular nerve main trunk in 26 cases $(89.6 .1 \%)$. The trunk had to be sacrificed in 3 cases $(10.3 \%)$, due to the close proximity with the tumour and in these three cases; we managed to preserve the posterior branch alone. This may had been one of the causes for a relatively longer operation time than reported.

Sensory disturbance of the pinna as a result of excising the great auricular nerve often reduces the quality of life of the patients who have undergone parotidectomy. ${ }^{36} \mathrm{We}$ agree with Vieira et al that preservation of the great auricular nerve or its branches is technically feasible during parotidectomy. ${ }^{13}$ The average operative time was comparable to that reported in the literature ${ }^{13}$ and this could be explained by the time saving using Ligasure ${ }^{37}$ compensated for the time loss of both great auricular nerve preservation and e-PTFE insertion.

\section{Conclusion:}

The use of facial nerve monitoring, Ligasure as well as sticking to the fine operative details can decrease post operative facial nerve dysfunction. The use of e-PTFE is advisable to eliminate the incidence of Frey syndrome; however transient salivary fistula is to be anticipated. Great auricular nerve can be saved in the majority of cases.

\section{References:}

1- Guntinas-Lichius O, Klussmann JP, Wittekindt C, Stennert E: Parotidectomy for benign parotid disease at a university 
teaching hospital: Outcome of 963 operations. Laryngoscope 2006; 116: 534 540.

2- Wang SJ and Eisele DW: Parotidectomy: Anatomical considerations. Clinical Anatomy 2012; 25: 12-18.

3- O'Brien CJ: Current management of benign parotid tumors - the role of limited superficial parotidectomy. Head Neck 2003; 25: 946-952.

4- Marchese-Ragona R, De Filippis C, Marioni G, Staffieri A: Treatment of complications of parotid gland surgery. Acta Otorhinolaryngol Ital 2005; 25: 174-178.

5- Sharma R, Sirohi D: Proximal and distal facial nerve exploration during superficial parotidectomy. J Maxillofac Oral Surg 2010; 9(2): 150-154.

6- Ricks R, Banga R, Porter M: Gustatory itching: An unusual complication following superficial parotidectomy. J Laryngol Otol 2010; 124(11): 1227-1228.

7- Torretta S, Pignataro L, Capaccio P, Brevi A, Mazzola R: Fat injections for the management of post-parotidectomy Frey syndrome: A technical note. $J$ Craniomaxillofac Surg 2012; 40(2): 173176.

8- Nouraei SAR, Ismail Y, Ferguson MS, Mclean NR, Milner RH, Thomson PJ, Welch AR: Analysis of complications following surgical treatment of benign parotid disease. ANZ J Surg 2008; 78: 134138.

9- Eisele DW, Wang SJ, Orloff LA: Electrophysiologic facial nerve monitoring during parotidectomy. Head Neck 2009; 32: 399-405.

10-Piénkowski P, Golusińnki W, WiertelKrawczuk A, Huber J: Intraoperative facial nerve monitoring for parotid gland surgery. Otolaryngol Pol 2010; 64(5): 302-306.

11-Terris DJ, Tuffo KM, Fee WE J: Modified facelift incision for parotidectomy. $J$ Laryngol Otol 1994; 108(7): 574-578.

12-Yokoshima K, Nakamizo M, Ozu C, Fukumoto A, Inai S, Baba S, Yagi T: Significance of preserving the posterior branch of the great auricular nerve in parotidectomy. J Nippon Med Sch 2004; 71(5): 323-327.
13-Vieira MBM, Maia AF, Ribeiro JC: Randomized prospective study of the validity of the great auricular nerve preservation in parotidectomy. Arch Otolaryngol Head Neck Surg 2002; 128: 1191-1195.

14-Wang SJ, Eisele DW: Superficial parotidectomy. In: Salivary gland disorders. Myers EN, Ferris RL (Editors); Berlin Heidelberg: Springer-Verlag (Publisher); 2007; p.237-46.

15-Houes JW, Brackmann DE: Facial nerve grading system. Otolaryngol Head Neck Surg 1985; 93: 146-147.

16-Durucu C, Karatas E, Yigiter R, Baglam T, Kara F, Yilmaz M, Kanlikama M: Electro-physiologic assessment of the subclinical changes in facial functions after parotidectomy. J Craniofac Surg 2010; 21(3): 656-659.

17-Amin A, Mostafa A, Rifaat M, Nabawi A, Shallan M, Rabie A, Elzohairy M: Parotidectomy for benign parotid tumors: An aesthetic approach. Journal of the Egyptian National Cancer Institute 2011; 23: 67-72.

18-Papadogeorgakis N, Skouteris CA, Mylonas AI, Angelopoulos AP: Superficial parotidectomy: Technical modifications based on tumour characteristics. Journal of Cranio-Maxillofacial Surgery 2004; 32 : 350-353.

19-Pai PS: Complications in head and neck surgery. Otorhinolaryngology Clinics 2010; 2(1): 61-67.

20-Dias FL, Limaa RA, Pinhoc J: Practical tips to identify the main trunk of the facial nerve. In: Pearls and pitfalls in head and neck surgery. Cernea CR, Dias FL, Fliss D, Lima RA, Myers EN, Wei WI (Editors); Basel, Karger (Publisher); 2008; chapter 7, p.106-107.

21-Wong DSY: Surface landmarks of the facial nerve trunk: A prospective measurement study. ANZ J Surg 2001; 71: 753-756.

22-Rea PM, McGarry G, Shaw-Dunn J: The precision of four commonly used surgical landmarks for locating the facial nerve in anterograde parotidectomy in humans. Annals of Anatomy 2010; 192: 27-32. 23-Pereira JA, Meri'A, Potau JM, Prats-Galino 
A, Sancho JJ, Sitges-Serra A: A simple method for safe identification of the facial nerve using palpable landmarks. Arch Surg 2004; 139: 745-747.

24-O'Brien JX, Rozen WM, Ting JW \& Michael Leung M: (Correspondence and communication) A simplified landmark for the facial nerve trunk in parotidectomy: The sternocleidomastoid origin. J Plast Reconstr Aesthet Surg 2011.

25-Lowry TR, Gal TJ, Brennan JA: Patterns of use of facial nerve monitoring during parotid gland surgery. Otolaryngol Head Neck Surg 2005; 133: 313-318.

26-Olsen KD: Superficial parotidectomy. Operative techniques in general surgery 2004; 6(2): 102-114.

27-RG; Tsau K \& Weinstock B: Tissue welding forceps usage in superficial parotidectomy: A clinical assessment. The American Surgeon 2008; 74(1): 51-55.

28-Gaillard C, Périé S, Susini B, St Guily JL: Facial nerve dysfunction after parotidectomy: The role of local factors. Laryngoscope 2005; 115(2): 287-291.

29-Glaister DH, Hearnshaw JR, Heffron PF, Patey DH: The mechanism of postparotidectomy gustatory sweating (the auriculo-temporal syndrome). BMJ 1958; 2: 942-946.

30-Guo X, Ruan X, Ran H, Jiang D \& Zhao $D$ : The clinical application of use of expanded polytetrafluoroethylene graft in repair of hollow defects and Frey symdrome of parotids. DOI: cnki:ISSN:10086455.0.2005-06-016
31-Singh N, Kohli M, Kohli H: Innovative technique to reduce incidence of Frey's syndrome after parotid surgery. The American Surgeon 2011; 77: 351-354.

32-Dulguerov P, Quinodoz D, Cosendai G, Piletta P, Marchal F, Lehmann W: Prevention of Frey syndrome during parotidectomy. Arch Otolaryngol Head Neck Surg 1999; 125: 833-839.

33-Y oo YM, Lee JS, Park MC, Kim C, Seo SJ, Lee IJ: Dermofat graft after superficial parotidectomy via a modified face-lift incision to prevent Frey syndrome and depressed deformity. J Craniofac Surg 2011; 22(3): 1021-1023.

34-Ahmed OA, Kolhe PS: Prevention of Frey's syndrome and volume deficit after parotidectomy using the superficial temporal artery fascia flap. British journal of plastic surgery 1999; 52: 256-260. 35-Maas CS, Gnepp DR, Bumpous J: Expanded polytetrafluoroethylene (GoreTex soft-tissue patch) in facial augmentation. Arch Otolaryngol Head Neck Surg 1993; 119: 1008-1114.

36-Patel N, Har-El G, Rosenfeld R: Quality of life after great auricular nerve sacrifice during parotidectomy. Arch Otolaryngol Head Neck Surg 2001; 127: 884-888.

37-Colella G, Giudice A, Vicidomini A, Sperlongano P: Usefulness of the Ligasure vessel sealing system during superficial lobectomy of the parotid gland. Arch Otolaryngol Head Neck Surg 2005; 131: 413-416. 